\title{
Intrahepatic cholangiocarcinoma: from diagnosis to treatment
}

For decades, hepatocellular carcinoma was largely the main focus of research around primary liver cancer. Over the last decade, however, intrahepatocellular carcinoma (ICC) has emerged from the shadows as the "other" important primary liver cancer. Of note, for the first time in 2010, the $7^{\text {th }}$ Edition AJCC/UICC manual included a distinct staging system for ICC. In addition, over the last twenty years there has been an explosion of interest and publications on the topic of ICC. Progress in the delineation of the pathogenesis, molecular underpinning, as well as the treatment and management of ICC has been impressive. This issue of $H S B N$ tells the story of ICC and describes the current status of understanding of ICC.

The articles were written by international experts from around the world. The articles address various aspects of ICC from pathogenesis to systemic treatment to resection to locoregional treatments such as radiation, ablation, and intra-arterial therapies. The end result is a very comprehensive compendium of articles for any reader who is interested in familiarizing himself or herself with ICC.

I would like to thank all the authors for their contributions.

Please enjoy this edition of $H S B N$.

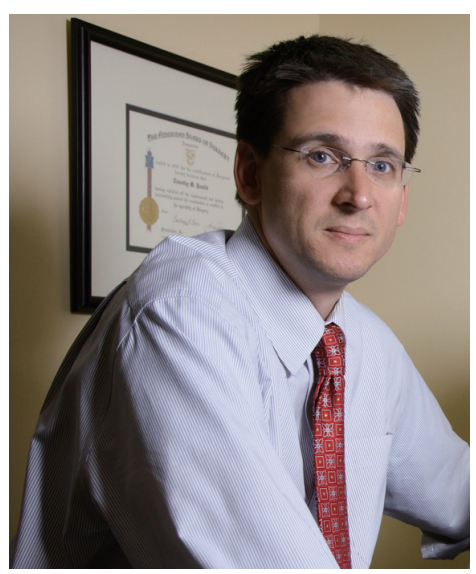

Timothy M. Pawlik, MD, MPH, PhD, FACS, FRACS (Hon.)

Timothy M. Pawlik, MD, MPH, PhD, FACS, FRACS (Hon.) Professor and Chair, Department of Surgery, The Urban Meyer III and Shelley Meyer Chair for Cancer Research, Professor of Surgery, Oncology, Health Services Management and Policy, The Obio State University, Wexner Medical Center, Columbus, OH, USA. (Email: tim.pawlik@osumc.edu) doi: 10.21037/hbsn.2017.01.04

Conflicts of Interest: The author has no conflicts of interest to declare. View this article at: http://dx.doi.org/10.21037/hbsn.2017.01.04

Cite this article as: Pawlik TM. Intrahepatic cholangiocarcinoma: from diagnosis to treatment. HepatoBiliary Surg Nutr 2017;6(1):1. doi: 10.21037/hbsn.2017.01.04 